\title{
Study of mechanical aspects of leak tightness in a pressure relief valve using advanced FE-analysis
}

\author{
Yevgen Gorash*, William Dempster, William D. Nicholls, Robert Hamilton, Ali A. Anwar \\ Department of Mechanical E Aerospace Engineering, University of Strathclyde, James Weir Building, 75 Montrose Street, Glasgow G1 1XJ, UK
}

\begin{abstract}
This paper presents a numerical study involving the deformation of contact faces in the metal-to-metal seal in a typical pressure relief valve. The valve geometry is simplified to an axisymmetric problem, which comprises a simple geometry consisting of only 3 components. A cylindrical nozzle, which has a valve seat on top, contacts with a disk, which is preloaded by a compressed linear spring. All the components are made of AISI type $316 \mathrm{~N}(\mathrm{~L})$ steel defined using the multilinear kinematic hardening model based on monotonic and cyclic tests at $20^{\circ} \mathrm{C}$. In-service observations show that there is a limited fluid leakage through the valve seat at operational pressures about $90 \%$ of the set pressure, which is caused by the fluid penetrating into surface asperities at the microscale. Nonlinear FEA in ANSYS using the fluid pressure penetration (FPP) technique revealed that there is a limited amount of fluid penetrating into gap, which is caused by the plastic deformation of the valve seat at the macroscale. Prediction of the fluid pressure distribution over the valve seat just before the valve lift is addressed in this study considering the FPP interaction on multiscale. This is the principal scope, since it allows adjustment of the valve spring force in order to improve the leak tightness.
\end{abstract}

Keywords: Contact, Finite element analysis, Metal-to-metal seal, Plasticity, Safety valve, Type 316 steel

\section{Introduction}

\subsection{Problem statement}

Leak tightness is one of the most important requirements to ensure correct operation of the valve components and specifi- 30 5 cally static seals. This paper presents an extended description of the investigation by Gorash et al. (2015) into static sealing and how advanced computational techniques might be used to understand and improve the design of static seals. In this paper only structural behaviour issues associated with conventional spring loaded safety valves have been investigated when metalto-metal sealing is required.

Static sealing is a fluid structure coupled problem where the degree of leak tightness is dictated by the local and global deformation of the contact surfaces. The leakage paths result from 15 gaps at the contact faces and are at a geometrical scale of the surface asperities which are at the micron scale. The contact face global geometry is at a macro scale where its resulting deformation is due to the global force loading which in the case of a safety valve is determined by the spring forces and the operating pressures. This coupling between fluid and structure at geometric scales that range from the micro to the macro imposes considerable challenges to the analysis of the problem.

Below the detailed results of the study by Gorash et al. (2015) are presented focusing on the development of computational analysis methods for the design of static metal-to-metal seals that address different scales. The investigation is limited to

\footnotetext{
${ }^{*}$ Corresponding author. Tel.: +44 790 9780901; Fax: +44 1415520775

Email address: yevgen.gorash@strath.ac.uk (Yevgen Gorash*)
}

global deformation at a macroscale with some initial simplified coupling from the micro- to macroscale via pressure penetration and an imposed pressure variation across the sealing face.

\subsection{Background}

The safe relief of pressure is of utmost importance in industry to protect equipment from being subjected to pressures above their maximum ratings. Over-pressure can have potentially fatal consequences for the surrounding staff, cause damage to the plant equipment involved and have possibly damaging environmental repercussions. Pressure relief valves (PRVs), as discussed by Malek (2006), are commonly used as a safety device in industrial processes to provide a self-regulating pressure release. The PRV is a type of valve used to control or limit the pressure in a system or vessel, which can build up by a process upset, instrument or equipment failure, or fire. The pressure is relieved by allowing the pressurised fluid to flow through the valve orifice out of the system. The operation, typical structure and different types of the PRV are addressed in detail by Malek (2006) and Hellemans (2009).

Song et al. (2013) observed that in actual usage PRVs can sometimes start to release fluid prior to their set pressures $P_{\text {set }}$. This is particularly true when $P_{\text {set }}$ is defined as the opening pressure and can result in a degradation of leak tightness for operation pressure $P_{\mathrm{op}}$, which is typically $90 \%$ of $P_{\text {set }}$. This study models the structure of the valve seat-disc interface in order to look at the fluid pressure penetration effects. Advanced FEA is used to investigate and quantify the influence of these effects on a spring force, which is required to provide a reliable 55 leak tightness for pressures below $P_{\text {set }}$. 
This study focusses on spring-operated metal-seated PRVs since they are not limited in temperature and pressure, when compared to the elastomer-seated PRVs, which have much more preferable leak tightness (Hellemans, 2009). This range of valves so often operate at high temperatures $\left(>300^{\circ} \mathrm{C}\right)$ which exclude the ${ }_{115}$ use of discs with soft seals, meaning that metal-to-metal contacts between the seat and disc are required to form the basis of fluid sealing. Fluid leakage is a major concern for metal-tometal contacts across the entire range of operation, not just as the system pressure tends towards the set pressure $P_{\text {set }}$.

\subsection{Previous research}

There is a significant body of work existing in this and related areas, ranging in scope from dynamic analyses of PRV, operating motions, sealing efficiency to complex mathematical ${ }^{125}$ modelling of realistic surface defects.

One of the earliest collection of advanced studies addressing testing and analysis of PRVs performance was compiled by Singh \& Bernstein (1983). The book covers the topics of test facilities design, safety valve experiments, analysis of PRVs ${ }^{130}$ 75 performance, and loads on discharge piping.

A transient analysis was carried out by Song et al. (2010) that focused on the effects of fluid flow on the valve disc. A deformable mesh is used to more realistically simulate the opening of the valve disc with CFD. The analysis is primarily useful ${ }^{135}$ so to aid in understanding the behaviour of the valve, in particular the disc, once the set pressure has been reached. Then Song et al. (2013) produced a dynamic analysis of a PRV with the aim of creating a model to accurately predict the closing (blowdown) characteristics of a spring-loaded PRV.

As well as for spring-loaded PRVs, an important work has been done to investigate the behaviour of pilot-operated PRVs. Dasgupta \& Karmakar (2002) simulated the dynamic response of a PRV using a bond graph method. Several key parameters were identified, which were associated with the valve opera- ${ }^{145}$ 90 tion, and primarily related to the geometrical design of the main valve and the configuration of the pilot valve.

Abid \& Nash (2004) carried out a parametric study on the effects of geometry on sealing between two metal flanges using the FEA approach. This research is related to the simulation of ${ }^{150}$ 95 PRV opening by virtue of its discussion of sealing effects between metal faces. The authors concluded that using a positive taper on the faces (i.e. the inner edge in contact, slight gap at outer edge) provides the best sealing characteristics.

A 3D non-linear elasto-plastic sequential transient analy-155 100 sis was performed by Griffin et al. (2012) for shakedown and fatigue assessments of fine radii within the PRV. The analysis utilised temperatures and heat transfer coefficients that were calculated from a separate 3D CFD analysis of fluid flow and heat transfer during operation of the valve. The use of elasto- ${ }^{160}$ plastic techniques combined with an innovative and fine meshing strategy allowed through-life strain ranges at very fine internal features to be calculated.

The series of works (Marie et al., 2003; Marie \& Lasseux, 2007; Vallet et al., 2008, 2009; Ledoux et al., 2011) presents $^{165}$ characterise liquid leakage through the metal contact seal. An experimental facility for measuring liquid leakage over a wide range of tightening conditions was developed by Marie et al. (2003). The numerically predicted "permeability" of the contact was compared to experiments. Marie \& Lasseux (2007) focused on an original experimental setup and procedure designed to measure the fluid micro (or nano) leak rate with great precision over several orders of magnitude. The issue of sealing performance of metal gaskets using a deterministic approach was addressed by Vallet et al. (2008, 2009). The analysis was focused on rough surfaces exhibiting fractal properties with the overall purpose to study the validity of the use of synthetic fractal surfaces as a representation of real ones. Ledoux et al. (2011) used complex mathematical models to generate surfaces with realistic defects, and suggested that leakages occur through sealing faces due to surface defects, and that the seal performance can be improved by surface defects shape optimisation.

Understanding, predicting and controlling the behaviour of surfaces in contact at micro/nano-scale have been extensively studied by Thompson et al. Thompson (2007) focused on the development of a multi-scale FE-model to predict thermal contact resistance between real surfaces which exhibited both surface form and roughness. Thompson \& Thompson (2010b) presented methods for generating, using, and operating on nonuniform irregularities for the incorporation of probabilistic rough surfaces in ANSYS, which resemble natural and man-made surfaces. Thompson \& Thompson (2010a) discussed the benefits, techniques, challenges, and considerations associated with the incorporation of measured surfaces in FE-models. Thompson (2011) focused on determining the modelling considerations and parameters necessary to accurately model real surfaces and to validate FE-models in the absence of experimental data.

Recently, the series of works (Darby, 2013; Aldeeb et al., 2014; Darby \& Aldeeb, 2014) investigated the dynamic response of PRVs in vapour or gas service including mathematical modelling, experimental investigation and model validation. This study presents a model for the opening lift dynamic response of a PRV, which accounts for the effects of unstable dynamic response through a set of five coupled nonlinear differential equations. The set is solved numerically to predict the position of the valve disk as a function of time for given parameters.

Chabane et al. (2012) did experimental and theoretical studies of the force exerted by the pressure on a disk of a PRV, which is essential for a correct design of the spring and the inner ring. To understand the forces, a PRV was modified and the spring removed; a force measurement tool was mounted to measure the forces exerted at different inlet pressures at lift. These tests were conducted for several ring settings. Measurements were made using incompressible fluid on a water test loop.

There has been relatively little work done into analysing the behaviour of the contact surfaces during the valve opening in terms of the valve structure. However, some progress has been achieved by Johnson (2013), who implemented a structural analysis of a spring loaded PRV through two loading phases. The FE-analyses were carried out in ANSYS, and included effects such as lateral internal pressure on the seat, friction in the contacts and nonlinear geometry. 


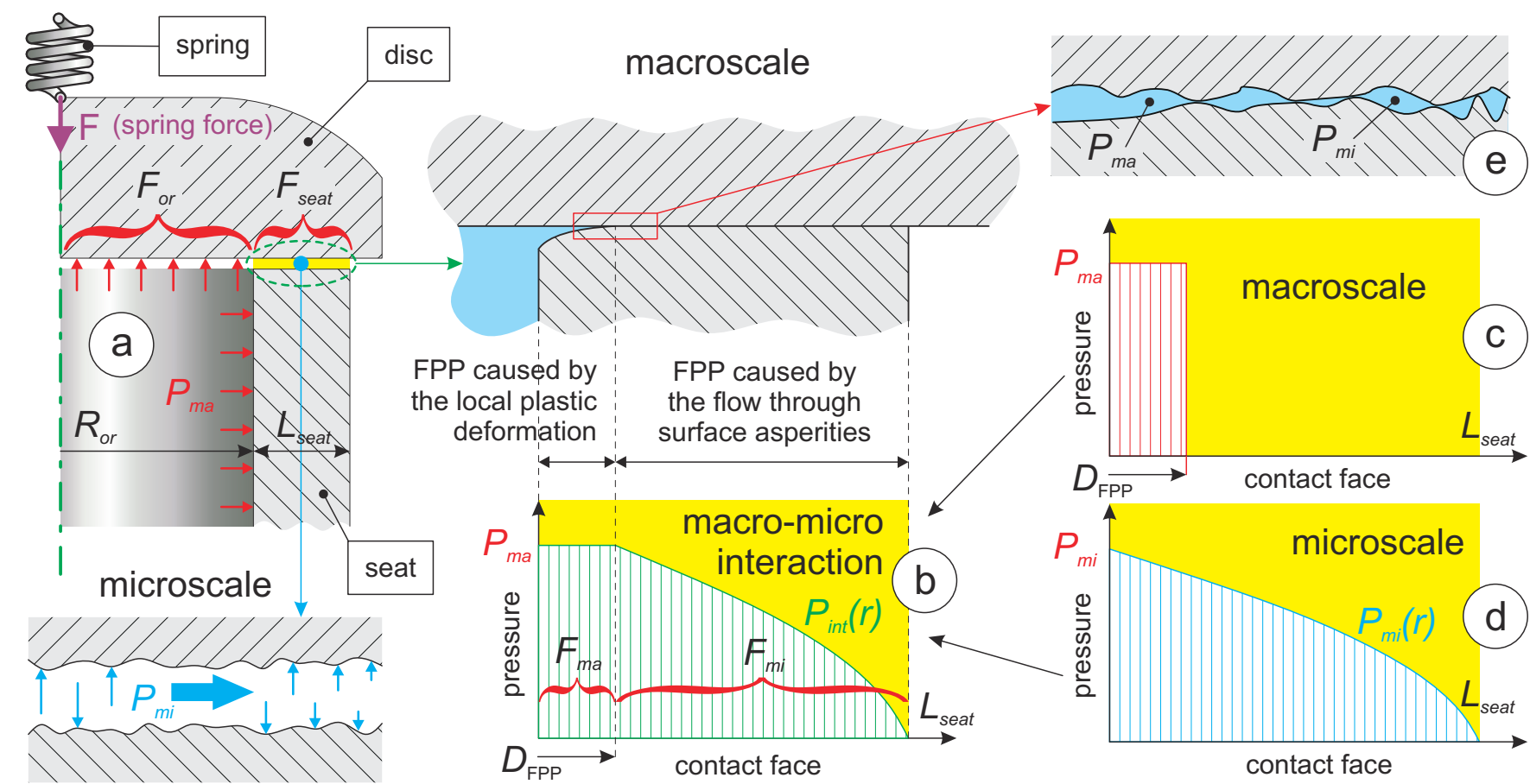

Figure 1: Concept of macro-micro effects interaction in the contact area of metal-to-metal seal considering Fluid Pressure Penetration (FPP): a) simplified valve structure, b) explanation of macro-micro interaction, c) fluid pressure on the macroscale, d) fluid pressure on the microscale, e) surface roughness.

\section{Concept of contact behaviour}

The proposed analysis concept is applied to an investigation of contact behaviour in a typical spring-operated PRV with a medium size orifice "J" according to API Standard 526. An important fact is that the disc and seat are both made of the austenitic stainless steel AISI 316N(L). As shown in Fig. 1, an idealised model of the PRV consists of the following three basic components:

- Cylindrical nozzle defined by the radius of orifice $R_{\text {or }}$ and the length of valve seat $L_{\text {seat }}$.

- Relatively rigid disc, which keeps the nozzle closed during the normal operation of the valve.

- Linear longitudinal spring, which is initially compressed ${ }_{210}$ and prevents lifting of the disc during normal operation.

The degree of spring compression is adjusted to fit the $P_{\text {set }}$, which usually is more than $5-10 \%$ higher than the normal $P_{\text {op }}$ as mentioned by Hellemans (2009). Therefore, the spring force ${ }_{215}$ is approximately equal to the force produced by the internal pressure, when it reaches the value of $P_{\text {set }}$, and applied to the disc surface corresponding to the orifice area. Since the system pressure, which represents the macroscopic pressure $P_{\text {ma }}$, is 5$10 \%$ below the set pressure during the normal operation, the orifice is kept tightly closed by the disc, providing a reliable seal through the difference of forces applied to the disc.

Described as above, this operation is true only for an idealised (perfectly elastic) model of the PRV. Since the real engineering material, which is used for the seat-disc pair, is quite far $_{225}$ contact behaviour concept has been proposed and illustrated in Fig. 1. This concept is formulated for elasto-plastic behaviour of material and based upon two structural behaviour assumptions, which are confirmed by structural analysis and practical observations.

Preliminary structural studies have shown that the internal edge of the contact face of the valve seat is subjected to significant plastic deformation on the macroscale as shown on top of Fig. 1b, which is caused by the non-uniform contact conditions over the contact face. This non-uniformity is produced by a particular degree of nozzle and disc global deformation. It leads to the localised high contact pressure on the internal edge, which undergoes some yielding under the spring preload. It was further noted that even a small amount of plastically deformed material slightly distorts the valve seat and creates a gap between the contact surfaces.

An initial Fluid Pressure Penetration (FPP) structural study showed that pressurised fluid penetrates into the contact gap, as shown schematically in diagram Fig. 1k. This increases the effective area of orifice exposed to the full system pressure and decreases the effective area of contact. Therefore, an actual value of $P_{\text {set }}$ may be significantly lower than the one, which has been used for the spring force calculation. Thus, contact area reduction is observed at the macroscale confirmed by an initial FE-analysis. Based on diagram Fig. 1k, it would mean that the fluid would not penetrate any further in the anaylsis. This is not what is practically observed.

Some limited degree of leakage is always practically observed in the metal-seated valves within the whole range of operational pressures. Since the contact is not perfectly tight, 


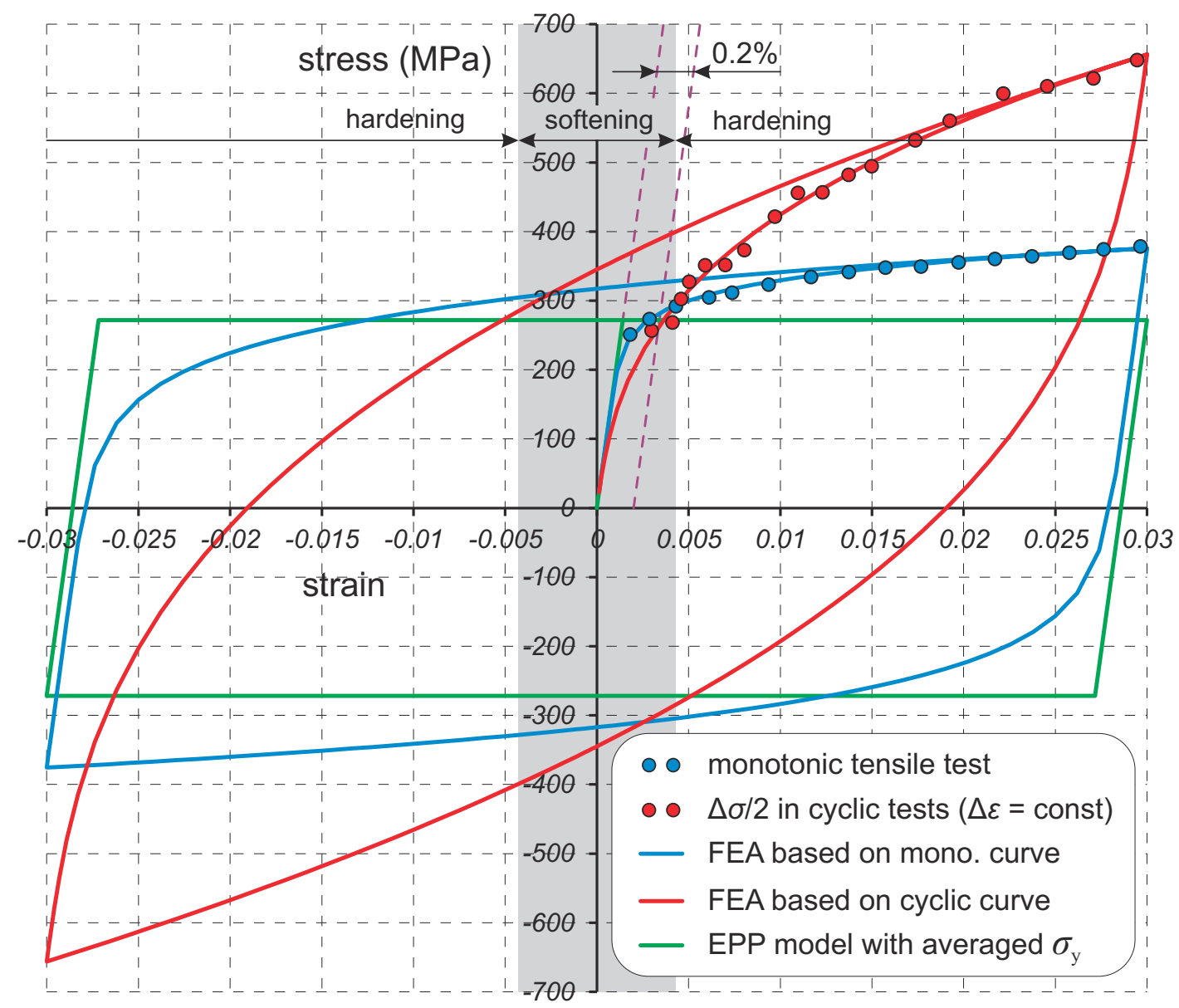

Figure 2: Experimental stress-strain curves of AISI type $316 \mathrm{~N}(\mathrm{~L})$ steel at $20^{\circ} \mathrm{C}$ after Chaboche et al. (1979) and their fittings with the R-O 1 and MLKH models

there is a FPP in the valve seat over the whole contact face. Moreover, microscopic studies confirm that the contact surface is not ideal as depicted in Fig. 1e, although it is lapped to $\mathrm{a}^{250}$ "mirror" finish. This degree of surface roughness and presence of non-uniform asperities at the microscale allows pressurised fluid to penetrate into the contact. It develops a particular pressure distribution over the contact face, as shown on diagram in Fig. 1 1 d. This depends on the type of fluid and its compressibil- ${ }^{255}$ ity and is discussed in more detail in Sec.4.2.

Therefore, the FPP effects are observed at two different scales - macroscopic and microscopic (Fig. 1b microscale is based on a pressurised gas). Since they both are assumed to exist in the same location, there should be some kind of non-linear interac- ${ }^{260}$ tion between them. Prediction of the pressure distribution over contact face as a result of this interaction is a way to assess an additional component of the upward force produced by pressure in the contact area. Therefore, the spring force can be calculated more accurately as a sum of "orifice" $F_{\text {or }}$ and "seat" 265 $F_{\text {seat }}$ components as shown in Fig. 11. An advanced iterative of the pressure profile as a result of macro-micro interaction as shown on diagram in Fig. 1 b. This iterative FEA procedure is described in detail in Sec. 4 of this paper.

270

\section{Material characterisation and modelling}

The critical components of the PRV (seat and disk) are usually manufactured from AISI type $316 \mathrm{~N}(\mathrm{~L})$ steel due to appropriate mechanical properties of this steel grade. Common use is for superheater piping, pressure vessels, heat exchangers and other components exposed to elevated temperatures up to $650^{\circ} \mathrm{C}$, as indicated in previous works (Gorash et al., 2012; Gorash \& Chen, 2013). The physical characteristics of this steel makes it an optimal material for a valve seat with high local contact stresses under corrosion-fatigue conditions and hightemperature exposure. Referring to experiments (Chaboche et al., 1979), at room and high temperatures the material behaviour of the steel AISI type $316 \mathrm{~N}(\mathrm{~L})$ is viscous and rate-dependent. Therefore, an accurate description of the plastic deformation is essential for the comprehensive material modelling to address structural integrity and operational issues.

Since all the dynamic effects of valve lifting and resetting are neglected, a PRV operation is assumed to be quasi-static for FE-simulation in ANSYS. Therefore, the viscoplastic material behaviour of the steel AISI type $316 \mathrm{~N}(\mathrm{~L})$ is simplified to rate-independent plasticity neglecting viscous effects. Among the variety of plasticity models, the following formulations are considered for the FEA based upon the available monotonic and cyclic experiments Chaboche et al. (1979) at $20^{\circ} \mathrm{C}$ and high 
Table 1: Material parameters of AISI type $316 \mathrm{~N}(\mathrm{~L})$ steel at $20^{\circ} \mathrm{C}$ corresponding to the plasticity models including R-O (1) and EPP models

\begin{tabular}{l|ll|l}
\hline \hline \multirow{2}{*}{ Type } & \multicolumn{2}{|l|}{ Ramberg-Osgood } & EPP \\
\cline { 2 - 4 } & $B(\mathrm{MPa})$ & $\beta$ & $\sigma_{\mathrm{y}}(\mathrm{MPa})$ \\
\hline Monotonic & 551.18 & 0.1075 & 282.6 \\
Cyclic & 2379.07 & 0.3553 & 261.5 \\
Averaged & - & - & 272.04 \\
\hline \hline
\end{tabular}

with $E=194(\mathrm{GPa})$ and $v=0.27$

after Karditsas \& Baptiste (1995)

strain rate regime $\dot{\varepsilon}=10^{-4}-10^{-3} \mathrm{~s}^{-1}$ shown in Fig. 2,

1. Elastic-perfectly-plastic (EPP) fit presented by isotropic ${ }_{325}$ model with no-hardening and yield stress $\bar{\sigma}_{\mathrm{y}}$ in ANSYS;

2. Smooth Ramberg-Osgood (R-O) fit presented by multilinear kinematic hardening (MLKH) model in ANSYS;

3. Combined hardening/softening Chaboche model.

Experimental data for AISI type $316 \mathrm{~N}(\mathrm{~L})$ steel at $20^{\circ} \mathrm{C}$ by ${ }^{330}$

Chaboche et al. (1979) is presented by two sets of data points shown in Fig. 2 The first set is a monotonic tensile stressstrain curve (SSC) in coordinates $\left[\varepsilon^{\text {tot }} ; \sigma\right]$ shown as blue dots in Fig. 2, while the second set is a result of many cyclic tests, which were performed at different constant $\Delta \varepsilon^{\text {tot }}$ in coordinates ${ }^{33}$ $\left[\Delta \varepsilon^{\text {tot }} / 2 ; \Delta \sigma / 2\right]$ shown as red dots in Fig. 2] It should be noted that $\Delta \varepsilon^{\text {tot }}$ was measured when the stress response stabilised after a number of cycles. An important observation concerning cyclic effects can be discerned from the comparison of the monotonic and cyclic SSCs. AISI type $316 \mathrm{~N}(\mathrm{~L})$ steel demonstrates mixed hardening-softening cyclic behaviour, which was comprehensively studied and modelled by Nouailhas et al. (1985). The range of small plastic strains corresponding to $\Delta \varepsilon^{\text {tot }} \leq 0.9 \%$ is characterised by isotropic softening marked by the grey area in Fig. 2, while the range of large plastic strains corresponding ${ }^{345}$ to $\Delta \varepsilon^{\text {tot }}>0.9 \%$ is characterised by isotropic hardening.

Since both experimental SSCs in Fig. 2 demonstrate some level of scatter, the first step in data analysis for the material model formulation is curve fitting. The conventional R-O equation by Ramberg \& Osgood (1943) is optimal for such curve fitting since it was formulated to describe the non-linear relationship between stress and strain in materials near their yield points. It is especially useful for metals that harden or soften with plastic deformation, showing a smooth elastic-plastic transition, that is found in AISI type $316 \mathrm{~N}(\mathrm{~L})$ steel. The equations ${ }^{355}$ for the monotonic and cyclic SSCs are as follows:

$$
\varepsilon^{\mathrm{tot}}=\frac{\sigma}{E}+\left(\frac{\sigma}{B}\right)^{1 / \beta} \quad \text { and } \quad \frac{\Delta \varepsilon^{\mathrm{tot}}}{2}=\frac{\Delta \sigma}{2 E}+\left(\frac{\Delta \sigma}{2 B}\right)^{1 / \beta},
$$

where $\Delta \varepsilon_{\text {tot }}$ is the total strain range and $\Delta \sigma$ is the total stress range (MPa) for each cyclic test respectively; $B$ and $\beta$ are material constants. The elastic properties used in both $\mathrm{R}-\mathrm{O}$ and 310 elastic-perfectly-plastic (EPP) models are the Young's modulus $E$ in $\mathrm{MPa}$ and the Poisson's ratio $v$.

The elastic material properties at $20^{\circ} \mathrm{C}$ given in Table 1 are taken from Karditsas \& Baptiste (1995). Using the defined value of $E$, the total strain $\varepsilon^{\text {tot }}$ in the experimental curves is decomposed into elastic and plastic strain. Then the plastic component $\varepsilon^{\mathrm{p}}$ of strain is fitted using the the least squares method by the following relations, which are derived from the Eq. (1):

$$
\sigma=B\left(\varepsilon^{\mathrm{p}}\right)^{\beta} \quad \text { and } \quad \frac{\Delta \sigma}{2}=B\left(\frac{\Delta \varepsilon^{\mathrm{p}}}{2}\right)^{\beta},
$$

where the resultant values of R-O material constants ( $B$ and $\beta$ ) are reported in Table 1 The coefficients of determination are $R^{2}=0.992$ for the monotonic SSC and $R^{2}=0.986$ for the cyclic SSC respectively. The values of $R^{2} \simeq 1$ and the visual comparison of the fitting accuracy in Fig. 2 prove the basic applicability of the R-O fits. The R-O fits for monotonic SSC (blue line in Fig. 2) and cyclic SSC (red line in Fig. 2) are then used to identify the constants for all three material models including EPP, MLKH and Chaboche, which are used for FEA.

The only necessary material constant for the EPP model to be defined is the yield stress $\sigma_{\mathrm{y}}$. It is estimated using Eq. 2 with plastic strain value $\varepsilon^{\mathrm{p}}=0.002$ corresponding to the conventional $0.2 \%$ offset from the elastic response on the SSCs, as explained in Fig. 2 with dashed lines. The obtained values of $\sigma_{\mathrm{y}}$ for monotonic and kinematic curves are given in Table 1 Since these values are not significantly different, a simple averaged value $\sigma_{\mathrm{y}}=272.04 \mathrm{MPa}$ is considered for FEA with the EPP model. The corresponding simulated SSC using averaged $\sigma_{\mathrm{y}}$ is shown in Fig. 2 with a green line.

Referring to ANSYSR Help (2013b), three general types of isotropic and kinematic hardening models are available in ANSYS: bilinear, multilinear, and nonlinear. Each of the hardening models assumes a von Mises yield criterion and includes an associated flow rule. The EPP model is a special case of the bilinear isotropic hardening model with a user-specified initial yield stress $\sigma_{\mathrm{y}}$ and tangent modulus $E^{\mathrm{p}}=0$ representing constant size of the yield surface. It requires only three material parameters $\left(E, v\right.$ and $\left.\sigma_{\mathrm{y}}\right)$ from Table 1 to be used for FEA.

Since the EPP model is not able to reflect different hardening rate in monotonic and cyclic response, the multilinear kinematic hardening (MLKH) model is applied to describe both types of SSCs. The backstress tensor for the MLKH model ANSYSR Help (2013b) evolves so that the effective stress versus effective strain curve is multilinear with each of the linear segments defined by a set of user input stress-strain points. These points are provided in the form of 2-column table with plastic strain vs. stress defined by Eq. (2), which specifies the hardening behaviour. Both monotonic and cyclic material data tables using corresponding constants from Table 1 are considered for FEA with the MLKH model. The results of the MLKH model verification in ANSYS with a single cyclic FEsimulation of a uniaxial specimen at $\Delta \varepsilon_{\text {tot }}=6 \%$ are shown in Fig. 2. It confirms the absence of any cyclic effects and an ideal match of the experiments (Chaboche et al., 1979) by the MLKH model with two different material data tables. 


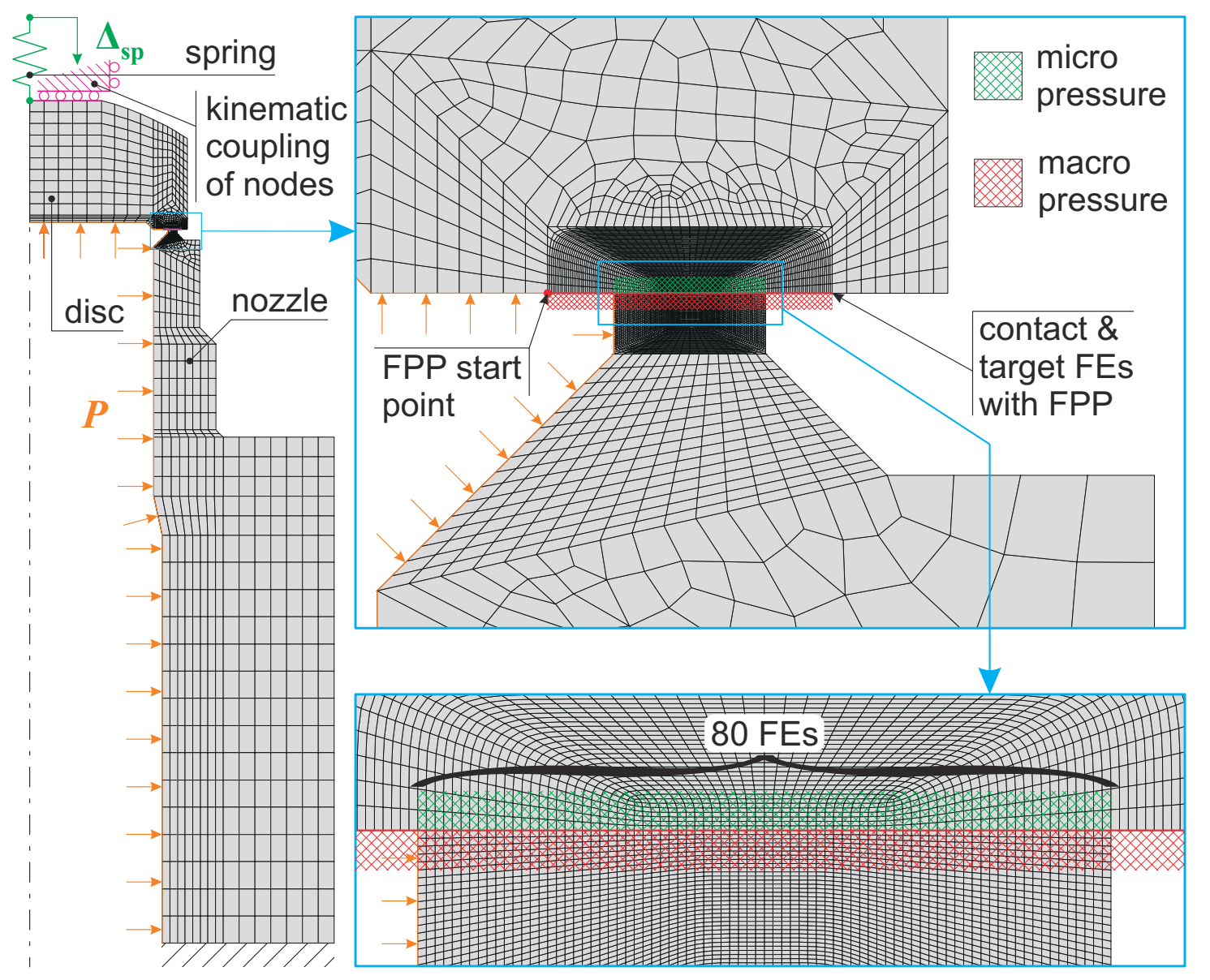

Figure 3: FE-model of the valve with detained view of the contact face, BCs and loadings

\section{Advanced structural FEA of the PRV operation}

\subsection{FE-model of the PRV with BCs and loadings}

Since our main focus is an investigation of the structural behaviour only in the contact area, the available 3D CAD-model of the PRV was drastically simplified. The FE-model intended for an analysis is axisymmetric and consists of only 3 compo(spring, disc and nozzle) as illustrated in Fig. 3. The most important component - seat, top part of the nozzle, is repro- 395 duced in detail, while the representation of the disc and spring is significantly simplified. The spring is compressed by application of the particular vertical displacement $\Delta_{\mathrm{sp}}$ to its top end.

375 This displacement $\Delta_{\mathrm{sp}}$ actuates a particular sealing force, which corresponds to a predefined $P_{\text {set }}$ as explained in the next section. 400 The spring force keeps the disc in balance, when the internal pressure $P$ reaches the corresponding value of $P_{\text {set }}$. The internal pressure $P$ is applied to all interior faces of the nozzle and disc except two lines, which form the contact pair. This contact pair has an activated FPP feature, which allows the change of the pressure conditions automatically according to the contact conditions. In this case it propagates an internal pressure $P$ into the contact gap, when it opens due to plastic deforma- ${ }^{405}$ tion of the internal edge of the contact face. This relatively new numerical technique available in ANSYS enables a macro- component of the pressure penetration as introduced in Fig. 1 t. The micro-component is taken into account by the application of a non-uniform pressure distributed over the contact face as shown in Fig. 11. Both application locations of micro- and macro-components of pressure are shown in Fig. 3 with hatched areas. The actual form of pressure distribution depends on the compressibility of fluid, and it is defined by the function of pressure dependent on the radial coordinate as explained in the next subsection. The contact area, where the micropressure is applied, is variable and changes in order to avoid an overlap with the macropressure. It should be noted that 80 solid and contact FEs are created over the contact face in order to obtain a high-resolution representation of the pressure profile before the valve lift as shown in Fig. 11.

The FE-model in Fig. 3 consists of the following FE types:

- 7412 PLANE183 - 8-node axisymmetric structural solid,

- 1 COMBIN14 - 2-node longitudinal linear spring-damper,

- 150 CONTA172 - 2D 3-node surf-surf contact (for disk),

- 80 TARGE169 - 2D 3-node target segment (for nozzle),

which in total comprise 7643 FEs. For more details regarding all these FE types please refer to ANSYSR Help (2013a). 


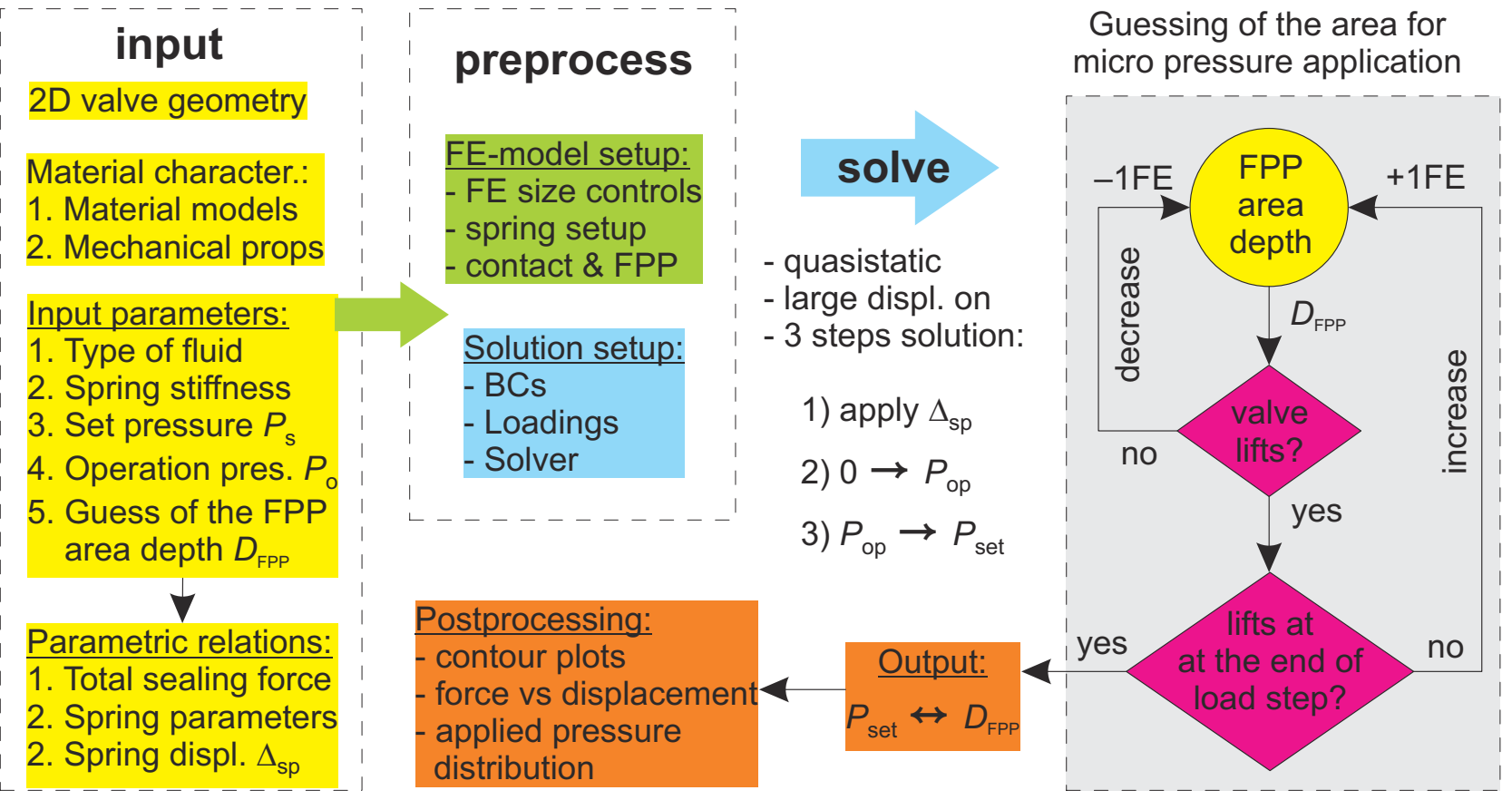

Figure 4: Flowchart of the iterative FEA to predict the pressure distribution over the valve seat contact area
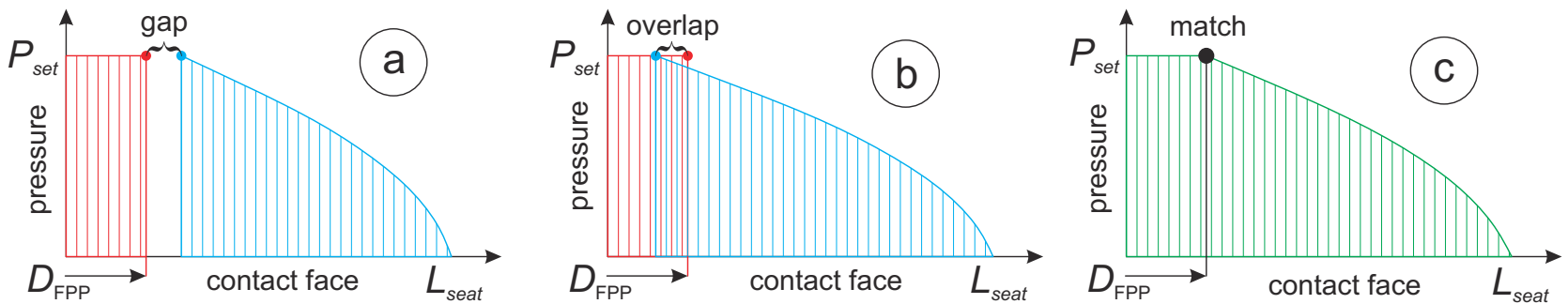

Figure 5: Explanation of the procedure shown in Fig. 4 a) valve lifts too late $\left(P>P_{\text {set }}\right)$, b) valve lifts too early $(P<P$ set $)$, c) converged solution $\left(P=P_{\text {set }}\right)$

\subsection{Pressure profiles and sealing force}

The microscopic component of the FPP is applied to the 410 contact face using an analytical function, which needs to be defined in ANSYS as dependent on internal pressure, geometric 430 parameters and type of fluid. Müller \& Nau (1998) provided a general analytical expression for a pressure drop in a uniform annular seal gap filled with a fluid as follows:

$$
p(x)=p_{1}\left[1-\left(1-\gamma^{2}\right) \frac{x}{L}\right]^{n},
$$

where $L$ is a length of a seal gap; $p_{1}$ - internal pressure and $p_{2}$ - external pressure; so the pressure ratio is $\gamma=p_{2} / p_{1}$, and $n$ is a power-law exponent, which is dependent on the type of fluid, e.g. $n=0.5$ for gas and $n=1$ for liquid.

Equation (3) may be extended to the case of a plane contact gap in the valve. Since the profile of microscopic pressure distribution remains the same, the mathematical form of pressure drop in the seal gap before valve opening is slightly changed to

$$
P(r)=P_{\text {set }}\left[\frac{r_{\text {out }}-r}{r_{\text {out }}-r_{\text {fpp }}}\right]^{n},
$$

where $P_{\text {set }}$ - set pressure corresponding to the balance of forces applied to the disk, $n$ - exponent dependent on the type of fluid
( 0.5 for gas and 1 for liquid), $r_{\text {out }}$ - outer radius of the contact area, $r_{\text {in }}$-inner radius of the contact area or radius of the orifice, $r_{\text {fpp }}$ - radius of fluid pressure penetration (FPP). It should be noted that $\left(r_{\text {in }}<r_{\text {fpp }} \leq r_{\text {out }}\right)$ if FPP is available, and $r_{\mathrm{fpp}}=r_{\text {in }}$ if FPP is unavailable. The pressure drop profiles for gas and liquid corresponding to different values of $P_{\text {set }}$ used in PRVs are illustrated in Fig.6.

Integrating Eq. (4) by $r$ over the length of the valve seat $\left(L_{\text {seat }}=r_{\text {out }}-r_{\text {in }}\right)$ from $r_{\text {in }}$ to $r_{\text {out }}$, an average value of the pressure within the pressure profile is obtained in analytical form:

$$
\bar{P}=\frac{P_{\text {set }}}{1+n} .
$$

Based upon the proposed concept, the total force, which needs to be actuated in the spring during its preload in order to lift the valve at a set pressure $P_{\text {set }}$, consists of three components:

1. Orifice force or force produced by pressure $P_{\text {set }}$ acting on the surface of the disc corresponding to the area of the orifice (refer to Fig. 119):

$$
F_{\text {or }}=P_{\text {set }} \pi r_{\text {in }}^{2} \text {, }
$$




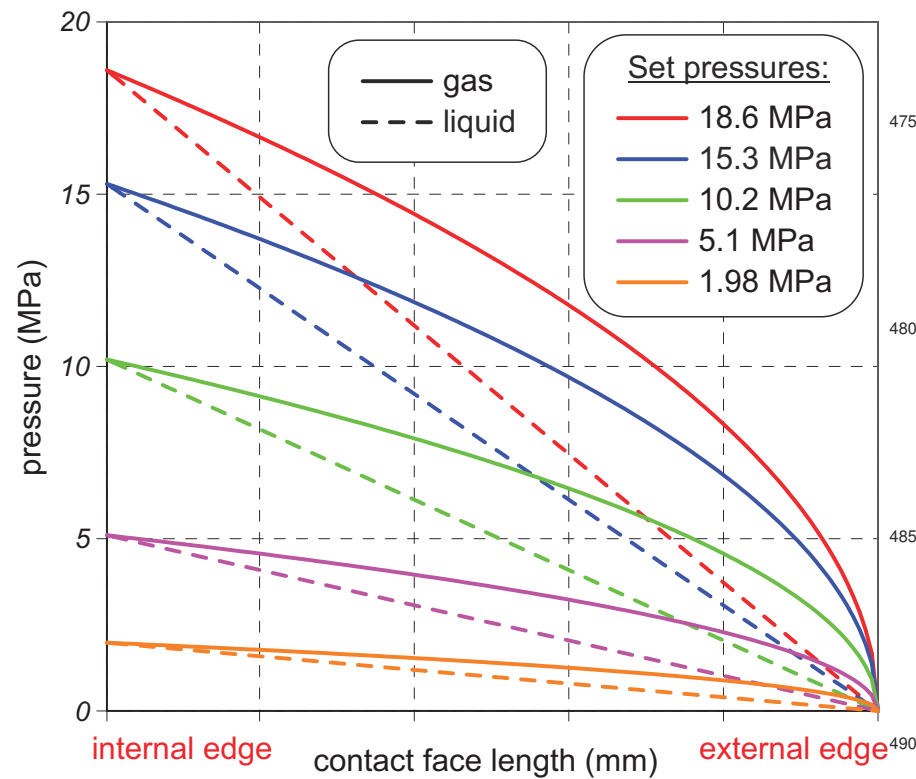

Figure 6: Pressure distributions over the valve seat for different $P_{\text {set }}$

2. Macro-fluidforce, which is calculated assuming a stepped distribution of pressure in the area of the macroscopic FPP (refer to Fig.11):

$$
F_{\text {ma }}=P_{\text {set }} \pi\left(r_{\text {fpp }}^{2}-r_{\text {in }}^{2}\right),
$$

3. Micro-fluid force, which is calculated using the average pressure (5) over the area of the microscopic FPP (refer to Fig. 11 ):

$$
F_{\mathrm{mi}}=\bar{P} \pi\left(r_{\text {out }}^{2}-r_{\text {fpp }}^{2}\right) .
$$

Thus, referring to Fig.1b an additional "seat" component of the spring force is:

$$
F_{\text {seat }}=F_{\mathrm{ma}}+F_{\mathrm{mi}},
$$

and the total spring force is (refer to Fig. 11):

$$
F_{\text {tot }}=F_{\text {or }}+F_{\text {seat }} \text {. }
$$

\subsection{FE-analysis setup and solution}

An advanced FE-analysis in this study was developed and automated using APDL-script. It enables essential flexibility and makes this study parametric since all important parameters can be changed and adjusted. The analysis flow consists of several steps as illustrated in Fig. 4

1. Preliminary operations including parametric calculations.

2. Preprocessing including FE-model and solution setup.

3. Solution including solver setup and running solution.

The key analysis procedure is an iterative guessing of the ${ }^{52}$ depth $D_{\text {fpp }}$ of the macroscopic FPP, which is expressed in terms of the number of FEs $N_{\text {fpp }}$ along the contact face from the internal edge up to the boundary of macroscopic FPP as shown in Figs 1b \& 17. Since the horizontal dimension of each FE along the contact face is $D_{\mathrm{FE}}=L_{\text {seat }} / 80$ as shown in Fig. 3 the ${ }^{525}$ output parameter is defined as $D_{\mathrm{fpp}}=N_{\mathrm{fpp}} \cdot D_{\mathrm{FE}}$. The objective of this process is a fitting of microscopic FPP described by the function (4) to actual macroscopic FPP, which is obtained from the FEA results. This procedure needs to be implemented since the degree of contact face global deformation, which defines the macroscopic FPP, is unknown for each combination of loading. In other words, this procedure is a manual coupling of the macro-component of the FPP with the micro-component by variation of $r_{\mathrm{fpp}}=r_{\mathrm{in}}+D_{\mathrm{fpp}}$ in the function (4).

When correctly guessing the value of $r_{\mathrm{fpp}}$, the valve lifts exactly at $P_{\text {set }}$ without a gap or overlapping of the macro- and micro-components of FPP, as shown in Fig. 4. In the case of a gap, when the valve doesn't lift for $P \leq P_{\text {set }}$ as explained in Fig. 5a, $D_{\text {fpp }}$ is decreased by 1 FE length $D_{\text {FE. }}$ While in the case of an overlap, when the valve lifts too early as explained in Fig. $5 \mathrm{~b}, D_{\mathrm{fpp}}$ is increased by $1 \mathrm{FE}$ length $D_{\mathrm{FE}}$. Once this iterative procedure has converged to the lift of the valve when $P=P_{\text {set }}$ as explained in Fig. 5k, the main results are output in the form of values pair: $P_{\text {set }}$ and corresponding $D_{\text {fpp }}$ for each combination of fluid and material.

\section{Analysis of the results}

In order to provide a high resolution of results, the FEA have been performed for the wide range of pressures $P_{\text {set }}$ comprising 21 values $(1.98-23.0 \mathrm{MPa})$. The five set pressures $(1.98,5.1,10.2,15.3,18.6 \mathrm{MPa})$ belong to typical standard values, which are used to set up the valves considered in this study. Moreover, each of these 21 simulations has been done for two different types of fluid (liquid or gas) and two different types of plastic material response (monotonic or cyclic). These make up a total of 84 FE-simulations, which were manually controlled to give a converged pressure profile on the contact face similar to Fig. 17. It should be noted that each variant of FE-analysis required at least five attempts to achieve a converged result. Therefore, about 500 FE-simulations have been performed in this study. The overall number of simulations could be significantly reduced and optimised, if the procedure for micromacro pressure interaction described in previous section was automated. Automation would require development of userdefined APDL-script or FORTRAN subroutine, which would replace the interactive manual procedure shown in Fig. 4 by an automatic adjustment of the area for micro-pressure application according to the current depth of FPP on macroscale.

\subsection{Global deformation}

In the first instance, the results characterising global deformation of the valve were obtained. An example of these results is given in Fig. 7 $\mathrm{f}$ for total displacement in $\mu \mathrm{m}$ and equivalent von Mises stress in Fig.7b. This illustrates the change of global structural response with increase of internal pressure from zero up to the set pressure of $18.6 \mathrm{MPa}$ for the case of a liquid and cyclic material response. Under the spring preload when the valve is not in operation, the disc is deflected by the spring force much more than the nozzle (as shown in Fig. $7 \mathrm{f}$ ), although it is relatively massive and stiff. However, it deforms elastically in 

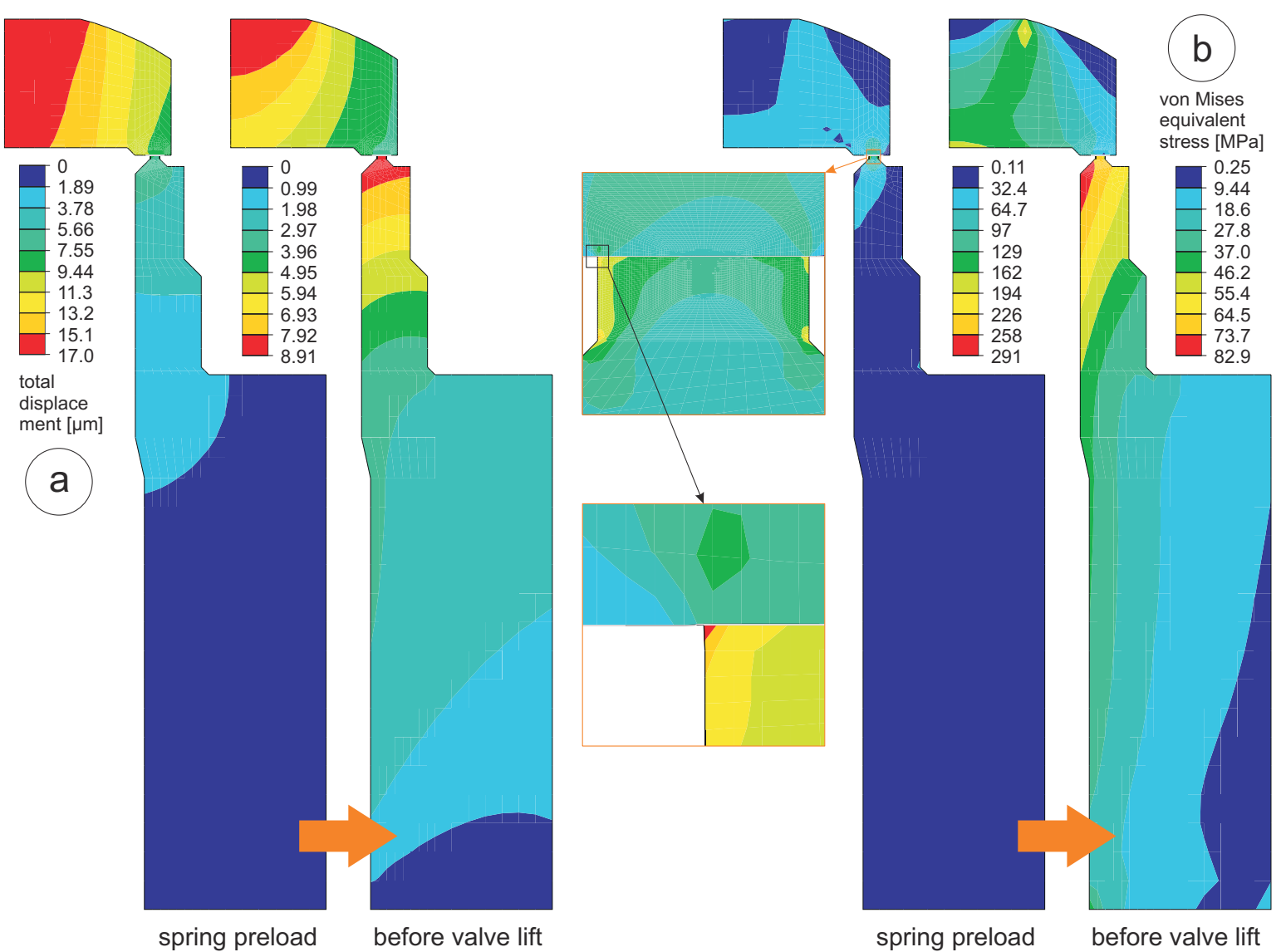

Figure 7: Change of total displacement (a) and equivalent von Mises stress (b) with increase of internal pressure up to the set pressure of $18.6 \mathrm{MPa}$

contrast to the valve seat at the top of the nozzle, which is relatively small and compliant. Therefore, the valve seat undergoes significant elastic and plastic deformation, which is caused by the compressive load from the disc acting on the contact area. It 555 results in four localised spots of significant stress concentration primarily in the corners of the valve seat as shown in Fig. $7 \mathrm{~b}$. This is explained in more detail in the next paragraph.

Under operation conditions when the internal pressure is increased up to $90 \%$ of $P_{\text {set }}$ or in the extreme case of valve lifting, 560 disc is deflected less, because of the balance of forces applied to it. However, the top of the nozzle including the valve seat is exposed to internal pressure and undergoes significant deformation, which expands and rotates the valve seat as shown in Fig. 7. A. Since the type and direction of the load applied to565 nozzle changes during operation, the stress concentration shifts from the valve seat to the top part of the internal surface of the nozzle. When compared to the preload condition, the stress level reduces drastically, and stress distribution becomes more uniform. Since the contact is frictionless, the distribution 570 displacement, stress and strain is discontinuous in the contact face, when an internal pressure is applied.

More attention needs be paid to the local deformation of the valve seat, since this location governs the performance of the whole component. As mentioned above, the valve seat is ex-575 posed to the static peak loading in the idle conditions, when no internal pressure is applied. Depending on the value of $P_{\text {set }}$ and corresponding spring load, the valve seat may undergo global plastic deformation, which is partly reversed during the action of the internal pressure. However not only is the degree of $P_{\text {set }}$ important for the distribution of the plastic strain over the valve seat. More important is the type of material response, which tends to change gradually with the number of cycles of the valve lifting and reseating. Significant change of plastic strain distribution is caused primarily by the cyclic softening of the material, when it becomes more compliant to the plastic deformation. This effect results in a larger amount of material undergoing plastic deformation, when the stabilised cyclic response of material is achieved after a number of operation cycles.

The importance of softening effect on the global plastic deformation of the valve seat is shown in Fig. 8 with the distribution of equivalent plastic strain plotted across the contact face. When the material response is monotonic (see Fig. 83), the plastic yielding of the contact face is restricted close to the internal and external edges for high values of $P_{\text {set }}$ and negligible for low values of $P_{\text {set }}$. So in the beginning of valve operation, the contact face undergoes mostly elastic deformations. However, with the accumulation of operation cycles, the full contact face tends to undergo major plastic yielding even at low $P_{\text {set }}$, as shown in Fig. 8b. It should be noted that cases shown in Figs $8 \mathrm{a}$ and $8 \mathrm{~b}$ present the limiting cases of the contact face condition. In order to obtain a history of plastic strain evolution between these two cases, a cyclic transient FE-simulation using 

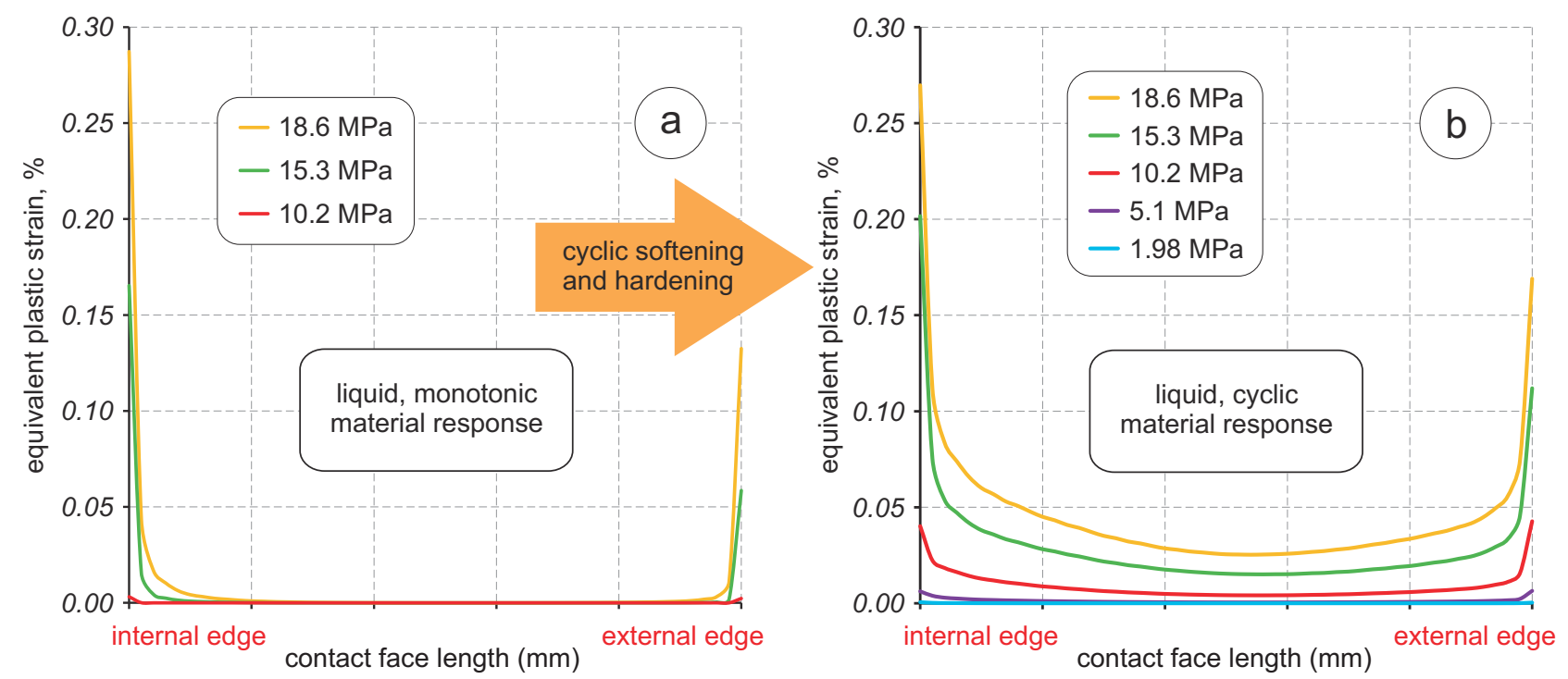

Figure 8: Change of equivalent plastic strain (\%) distribution over the contact face of nozzle (valve seat) with cyclic operation for the standard values of set pressure: (a) monotonic material response, (b) cyclic material response

Chaboche-type material models needs to be implemented.

\subsection{Equation fitting of FEA results}

Obtained FEA results for the depth of FPP are shown in Fig. 9 in the form of dots and triangles for all values of $P_{\text {set }}$ and in the form of pressure profiles over the contact face for 5 standard values of $P_{\text {set }}(1.98,5.1,10.2,15.3,18.6 \mathrm{MPa})$. Figure $9 \mathrm{a}$ shows results for a liquid, and Fig. $9 \mathrm{~b}$ - for a gas. Note-615 that in Fig. 9 black dots denote the boundaries between macroscopic and microscopic FPP for monotonic material response. Black triangles denote the boundaries for cyclic material response. Similarly, the difference in colour shade of pressure profiles denote either monotonic or cyclic material response. degree of macroscopic FPP increases non-linearly with an increase of $P_{\text {set }}$ for both types of fluids. However, the particular depth of global FPP $D_{\mathrm{fpp}}$ and corresponding length of effective contact area $\left(L_{\mathrm{eff}}=L_{\mathrm{seat}}-D_{\mathrm{fpp}}\right)$ is quite different for liquid and gas. The other important effect should also be noted that operation of the valve. It may be observed that the results for cyclic and monotonic material response are identical for liquid and $P_{\text {set }}=1.98 \mathrm{MPa}$ in Fig. $9 \mathrm{a}$ and for gas and $P_{\text {set }}=5.1 \mathrm{MPa}$ in Fig. 9 b. The reason is that below these values of set pressure no roscopic FPP is available since material response is elastic.

The numerical results were fitted by analytical functions, as shown in Fig.10, which were subsequently used for the formu ${ }^{-620}$ lation of relations for additional "seat" component of the spring force. In order to improve the quality of extrapolation, the fitting was implemented for an extended range of set pressures $P_{\text {set }}$ comprising 21 values $(1.98-23.0 \mathrm{MPa})$, which are shown in Fig. 9 with black dots and triangles. The number of finite elements (FEs) involved in FPP at the macroscale $N_{\text {fpp }}$ versus set pressure $P_{\text {set }}$ is fitted by a smoothing function. The function of the Heaviside step function $H\left(P_{\text {set }}\right)$ :

$$
\begin{aligned}
N_{\text {fpp }}\left(P_{\text {set }}\right)= & F_{\text {hi }}\left(P_{\text {set }}\right) H\left(P_{\text {set }}\right)+ \\
& F_{\text {lo }}\left(P_{\text {set }}\right)\left[1-H\left(P_{\text {set }}\right)\right],
\end{aligned}
$$

where the specific formulations of the step function $H\left(P_{\text {set }}\right)$ and fitting functions for the low pressure $F_{\text {lo }}\left(P_{\text {set }}\right)$ and high pressure $F_{\text {hi }}\left(P_{\text {set }}\right)$ domains are different for all 4 cases analysed:

a) Gas and monotonic material response:

$$
\begin{aligned}
& H\left(P_{\text {set }}\right)=0.5+0.5 \tanh \left(\frac{P_{\text {set }}-21.3}{4.6}\right), \\
& F_{\text {hi }}\left(P_{\text {set }}\right)=0.8 P_{\text {set }} \text { and } \\
& F_{\text {lo }}\left(P_{\text {set }}\right)=0.05 P_{\text {set }} ;
\end{aligned}
$$

b) Liquid and monotonic material response:

$$
\begin{aligned}
& H\left(P_{\text {set }}\right)=0.5+0.5 \tanh \left(\frac{P_{\text {set }}-20.0}{4.3}\right), \\
& F_{\text {hi }}\left(P_{\text {set }}\right)=0.96 P_{\text {set }} \text { and } \\
& F_{\text {lo }}\left(P_{\text {set }}\right)=0.05 P_{\text {set }} ;
\end{aligned}
$$

c) Gas and cyclic material response:

$$
\begin{aligned}
& H\left(P_{\text {set }}\right)=0.5+0.5 \tanh \left(\frac{P_{\text {set }}-10.5}{2.0}\right), \\
& F_{\text {hi }}\left(P_{\text {set }}\right)=0.8 P_{\text {set }} \text { and } \\
& F_{\text {lo }}\left(P_{\text {set }}\right)=0.1 P_{\text {set }} ;
\end{aligned}
$$



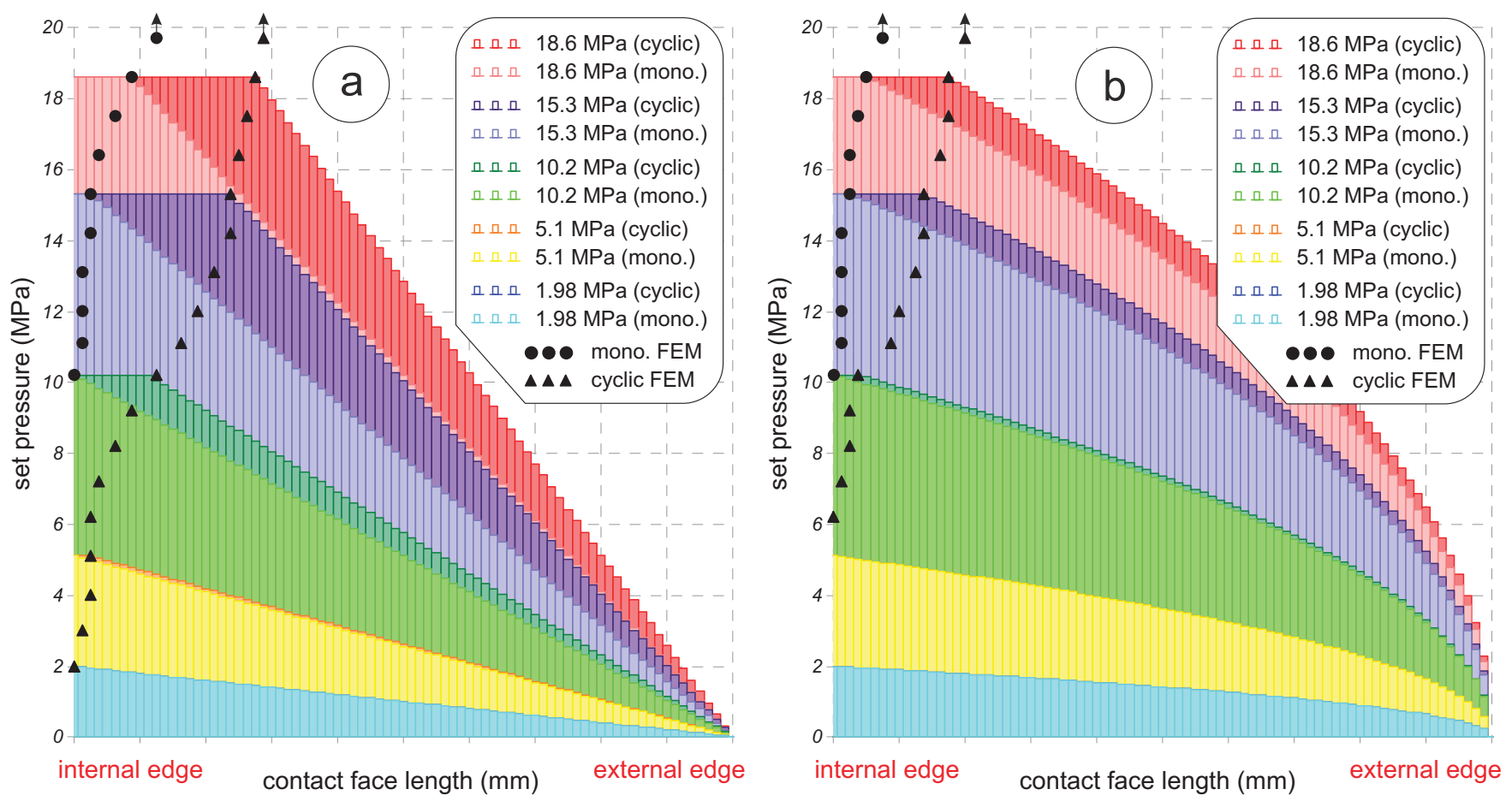

Figure 9: FEA results with FPP and fluid pressure drop in contact area at different set pressures for (a) liquid and (b) gas - markers denote the boundaries between macroscopic and microscopic FPP

d) Liquid and cyclic material response:

$$
\begin{aligned}
& H\left(P_{\text {set }}\right)=0.5+0.5 \tanh \left(\frac{P_{\text {set }}-10.0}{2.5}\right), \\
& F_{\text {hi }}\left(P_{\text {set }}\right)=4.3 P_{\text {set }}^{0.56} \text { and } \\
& F_{\text {lo }}\left(P_{\text {set }}\right)=0.27 P_{\text {set }} .
\end{aligned}
$$

The graphical comparison of the numerical results with their fits is illustrated in Fig.10, One can conclude that the proposed fit using analytical functions (11) - (15) provides a good rep-650 resentation of the FEA output and, therefore, it can be used in FEA-based assessment of the spring force. The number of FEs in FPP at the macroscale (11) is then transformed into the function for corresponding radius of FPP as

$$
r_{\text {fpp }}\left(P_{\text {set }}\right)=r_{\text {in }}+\frac{L_{\text {seat }}}{80} N_{\text {fpp }}\left(P_{\text {set }}\right) .
$$

Using the value of $r_{\mathrm{fpp}}$ defined by Eq. 16, an additional "seat" component of the spring force is obtained from Eqs (7) - (9):

$$
\begin{aligned}
F_{\text {seat }}\left(P_{\text {set }}\right)= & P_{\text {set }} \pi\left(\left[r_{\text {fpp }}^{2}\left(P_{\text {set }}\right)-r_{\text {in }}^{2}\right]+\right. \\
& \left.+\frac{1}{1+n}\left[r_{\text {out }}^{2}-r_{\text {fpp }}^{2}\left(P_{\text {set }}\right)\right]\right) .
\end{aligned}
$$

\section{Discussion and conclusions}

Using Fig. 111, the additional "seat" components of the spring force estimated analytically can be compared to those, which are based upon FEA. The analytical estimation is done considering microscopic FPP only, i.e. using Eq. (8) for the whole seat contact area. The FEA-based estimation is done considering a micro-macro interaction and Eq. (17) based on numerical results fitted by the functions (11)-(15). The comparison shows that the differences between gas and liquid, and analytical and FEA-based results are quite significant. Firstly, the analytic "seat" component of the spring force for gas is $33.3 \%$ larger than the one for liquid estimated by Eq. (8) for all set pressures because of the difference in shape of corresponding pressure profiles. Secondly, deviation of FEA-based force from analytical predictions is much more significant for liquid than for gas, as shown in Fig. 11b. Thirdly, deviation increases with increase of $P_{\text {set }}$, as shown in Fig. 11b. For example, in the case of $P_{\text {set }}=18.6 \mathrm{MPa}$, liquid and cyclic material response, the difference between additional spring forces is about $27 \%$.

Referring to Hellemans (2009), metal-seated spring valves with operating pressures between $90 \%$ and $95 \%$ of $P_{\text {set }}$ do not stay tight for long and usually get damaged after a couple of operations. This fact was confirmed by the advanced FE-analysis implemented in this study using monotonic and cyclic material properties. The effective contact area of the valve seat changes significantly during the cyclic operation of the valve. In this regard, a spring force required to provide a leakage tightness of the valve needs to be adjusted correspondingly after each resetting. The results of the analysis demonstrate that the required alteration of the spring force during cyclic operation may be over a quarter of its initial value. Analyses of the macro deformation of the valve seat/disc under various pressures using quasistatic structural FEA with FPP technique revealed that:

- Macro deformation is important and affects sealing (effective contact) area; 

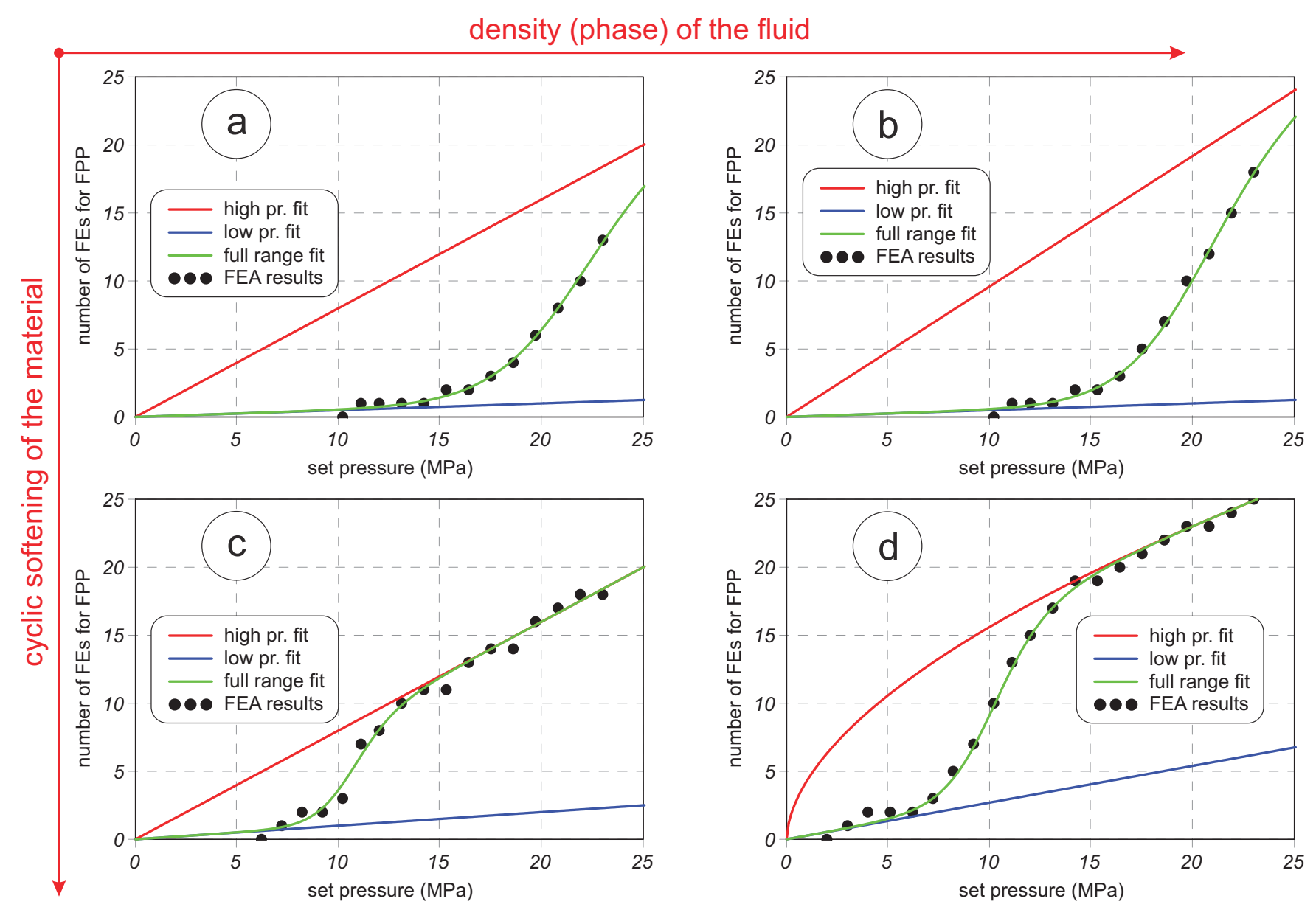

Figure 10: Fitting of FEA results by the functions 11- (15) for combinations of fluid and material: (a) gas and monotonic, (b) liquid and monotonic, (c) gas and cyclic, and (d) liquid and cyclic

- Cyclic material response affects the structural behaviour;

- The type of fluid effects the contact pressure distribution.

Improved analytical functions for a component of the pressure distribution acting on the contact surface (11) - (17) are formulated for the particular valve seat geometry and are dependent on $P_{\text {set }}$ based upon FEA results. However, these functions are valid only for limiting cases of the valve operation (1st cycle and stabilised cyclic response). In order to extend the proposed ${ }^{700}$ formulation to the whole range of operation time, a transient cyclic FE-analysis using e.g. unified Chaboche material model needs to be done. Based upon these results, time or number of cycles might be introduced into a function for sealing force, which would enable an automatic self-adjustment of the valve. ${ }^{705}$

Future work in continuation of this research in the first instance needs to consider experimental validation of the theoretical assumptions from this study by measuring spring force of the PRV. All theoretical outcomes of this research require an experimental verification to confirm the validity of the pro-710 posed concept and ideas. Particularly, an additional component of the sealing force requires experimental identification in order to compare it with a theoretically defined one. For this purpose the experimental rig has been designed in CAD SolidWorks as shown in Fig. 12h, which consists of 3 major components: $\quad 715$
1. High pressure cylinder with fluid,

2. Experimental stand,

3. PRV installed on top of the stand.

There is a number of additional components required for this experimental rig like safety valves, relief valves, high pressure supply, pressure transducers, inlet and outlet flanges, etc. Additional modifications are done to the valve as shown in Fig. 12b in order to install the force transducer for measuring spring force during operation. An old stem is replaced with a new stem containing the force transducer inside. An additional space inside of the valve is provided by installation of the spacer between the valve casing and bonnet. The designed experimental rig has been recently manufactured and assembled as shown in Fig. 12k, and it is ready to be used for further research.

Other future work in continuation of this research includes:

1. Literature review to understand PRV leak tightness in a static closed state near the the set pressure point;

2. Automation of the spring force adjustment according to $D_{\text {fpp }}$ at a macroscale to maintain a consistent seal;

3. Consideration and estimation of high temperature effects for material response and sealing performance;

4. Transient FEA of the cyclic PRV operation using Chaboche material model with kinematic and isotropic hardening; 

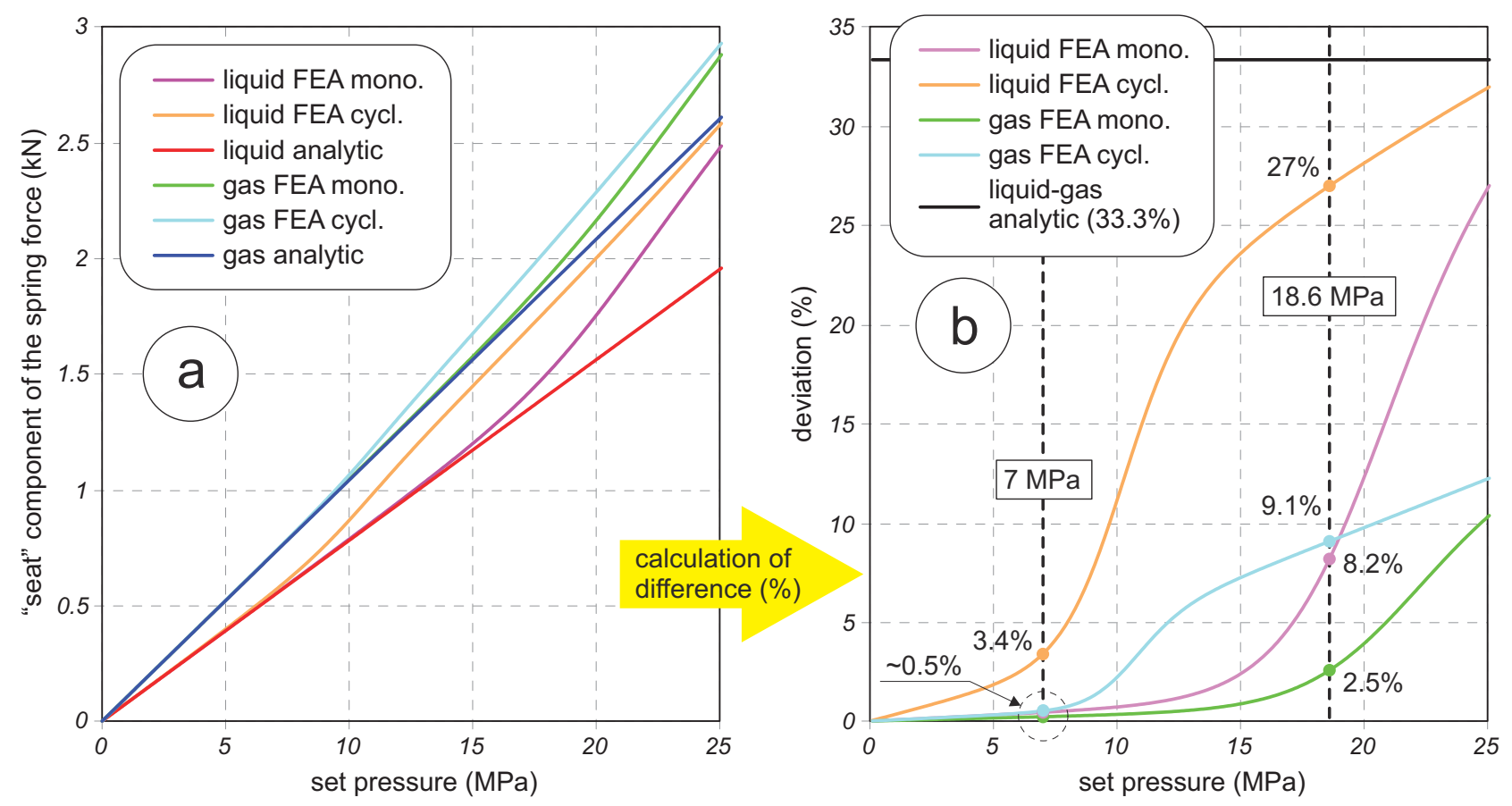

Figure 11: Additional "seat" component of the spring force: (a) comparison of the formulations defined using FEA and analytically, (b) deviation of FEA predictions from analytical $(\%)$

\section{Acknowledgements}

The authors greatly appreciate the Weir Group PLC for the financial and material support given in the WARC project N1a "Leak Tightness in Safety Valves" and the University of Strath-765

\section{References}

Abid, M., \& Nash, D. (2004). A parametric study of metal-to-metal contact flanges with optimised geometry for safe stress and no-leak conditions. Int. J. Pres. Ves. E Piping, 81, 67-74. doi 10.1016/j.ijpvp.2003.11.012

Aldeeb, A. A., Darby, R., \& Arndt, S. (2014). The dynamic response of pressure relief valves in vapor or gas service. Part ii: Experimental in- ${ }^{775}$ vestigation. J. of Loss Prevention in the Process Industries, 31, 127-132. doi $10.1016 / j \cdot j l p .2014 .06 .002$

ANSYSß Help (2013a). Mechanical APDL// Element Reference // 7. Element

Library // Part I: Element Library. ANSYS, Inc. Canonsburg (PA), USA (Academic Research 14.5.7 ed.).

ANSYS® Help (2013b). Mechanical APDL//Material Reference // 3. Material Models // 3.4. Rate-Independent Plasticity. ANSYS, Inc. Canonsburg (PA), USA (Academic Research 14.5.7 ed.).

Anwar, A., Gorash, Y., \& Dempster, W. (2016a). Application of multiscale approaches to the investigation of sealing surface deformation for the improvement of leak tightness in pressure relief valves. In K. Naumenko, \& M. Aßmus (Eds.), Advanced Methods of Continuum Mechanics for Materials and Structures - Advanced Structured Materials. Cham, Switzerland: Springer International. 30 p., in press.

Anwar, A., Gorash, Y., Dempster, W., \& Hamilton, R. (2015). Literature research in relevant fields to understand pressure relief valve leak tightness in a static closed state. Procedia Engineering, 130, 95-103. doi $10.1016 / j$.proeng.2015.12.179

Anwar, A., Gorash, Y., Dempster, W., Hamilton, R., \& Nash, D. (2016b). Effect of high temperature on structural behaviour of metal-to-metal seal in a pressure relief valve. In A. Bickley (Ed.), Proc. of 23rd Conf. on Fluid Sealing Fluid Sealing 2016 (2-3 March, 2016, Manchester) (pp. 121-132). Bedford, UK: BHR Group.

Chabane, S., Corbin, F., Couzinet, A., Pierrat, D., \& Bayart, M. (2012). Experimental incompressible forces applied in a safety valve. In Proc. ASME Pressure Vessels $\mathcal{E}$ Piping Conf. (PVP2012) PVP2012-78129. Toronto (July 15-19), Canada: ASME. doi 10.1115/PVP2012-78129

Chaboche, J.-L., Dang Van, K., \& Cordier, G. (1979). Modelization of the strain memory effect on the cyclic hardening of 316 stainless steel. In Trans. 5th Int. Conf. on Structural Mechanics in Reactor Technology number L11/3 in SMiRT5 (pp. 1-10). Berlin, Germany: IASMiRT.

Darby, R. (2013). The dynamic response of pressure relief valves in vapor or gas service. Part i: Mathematical model. J. of Loss Prevention in the Process Industries, 26, 1262-1268. doi 10.1016/j · jlp.2013.07.004

Darby, R., \& Aldeeb, A. A. (2014). The dynamic response of pressure relief valves in vapor or gas service. Part iii: Model validation. J. of Loss Prevention in the Process Industries, 31, 133-141. doi $10.1016 / \mathrm{j} \cdot \mathrm{jlp} .2014 .06 .001$

Dasgupta, K., \& Karmakar, R. (2002). Dynamic analysis of pilot operated pressure relief valve. Simul. Model. Practice $\mathcal{E}$ Theory, 10, 35-49. doi 10.1016/S1569-190X (02)00061-8

Gorash, Y., Altenbach, H., \& Lvov, G. (2012). Modelling of high-temperature inelastic behaviour of the austenitic steel AISI type 316 using a continuum damage mechanics approach. Journal of Strain Analysis, 47, 229-243. doi 10.1177/0309324712440764

Gorash, Y., \& Chen, H. (2013). Creep-fatigue life assessment of cruciform weldments using the linear matching method. Int. J. of Pressure Vessels $\mathcal{G}$ 

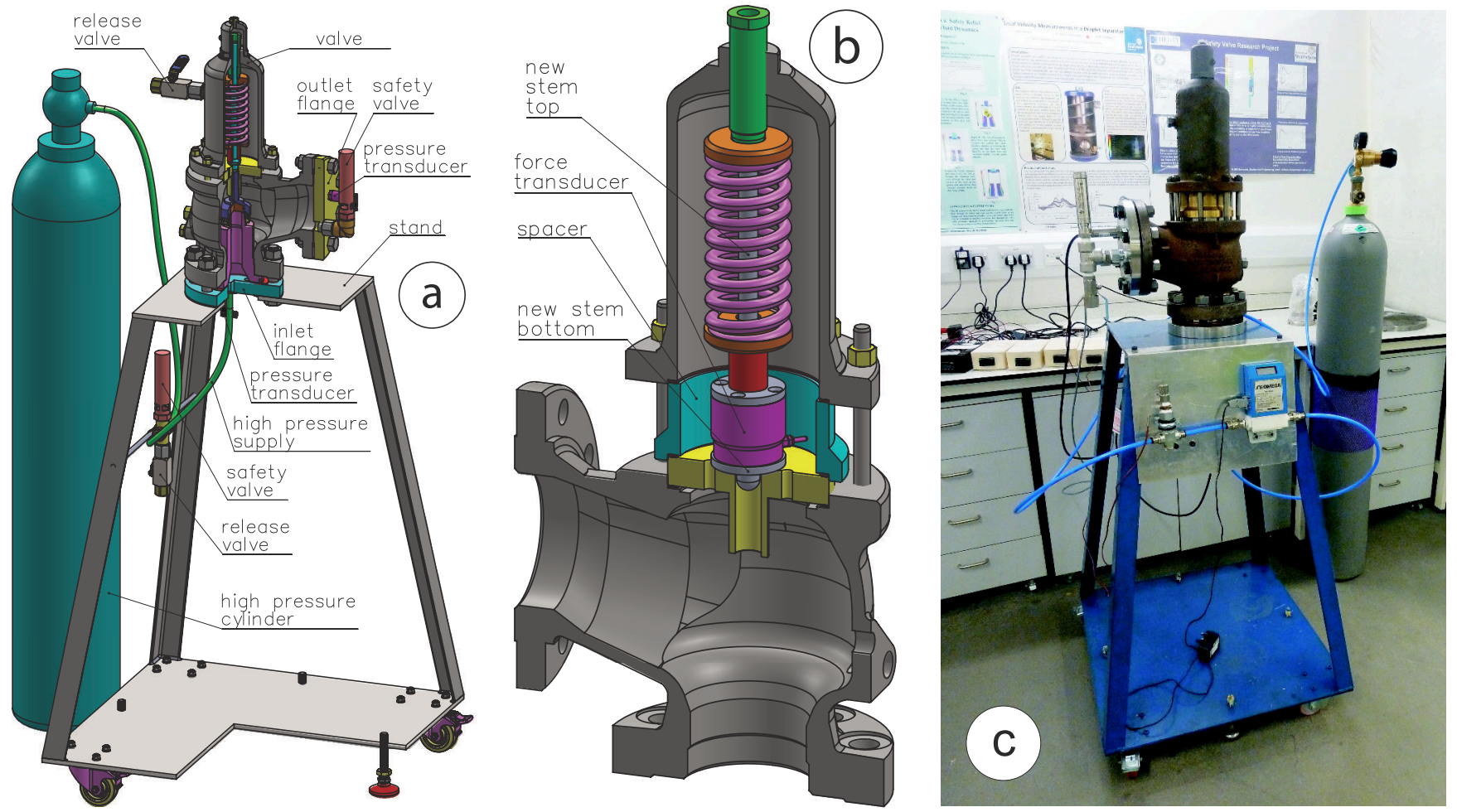

Figure 12: Experimental verification: a) assembly of the experimental setup, b) installation of the force transducer into the valve, c) photo of the experimental rig

Piping, 104, 1-13. doi 10.1016/j.ijpvp.2012.12.003

Gorash, Y., Dempster, W., Nicholls, W. D., \& Hamilton, R. (2015). Modelling of metal-to-metal seals in a pressure relief valve using advanced fe-analysis. In J. T. M. de Hosson, M. Hadfield, \& C. A. Brebbia (Eds.), Surface Effects and Contact Mechanics including Tribology XII number 91 in WIT Trans-825 actions on Engineering Sciences (pp. 247-258). Southampton, UK: WIT Press. doi 10.2495/SECM150221

Griffin, D., Kelly, J., Bowie, G., Hunt, D., Fletcher, A., Reed, G., \& Hugill, P. (2012). Relief valve stress and fatigue study using non-linear analysis. In Proc. ASME Pressure Vessels E Piping Conf. (PVP2012) PVP2012-78513.830 Toronto (July 15-19), Canada: ASME. doi 10.1115/PVP2012-78513

Hellemans, M. (2009). The Safety Relief Valve Handbook: Design and Use of Process Safety Valves to ASME and International Codes and Standards. Oxford, UK: Butterworth-Heinemann.

Johnson, M. (2013). Investigation of the Behaviour of Pressure Relief Valves. 835 MEng Thesis University of Strathclyde Dep. of Mechanical \& Aerospace Engineering. Supervisor - Dr. R. Hamilton.

Karditsas, P. J., \& Baptiste, M.-J. (1995). Thermal and Structural Properties of Fusion related Materials. ARIES Properties Archive: UKAEA FUS 294 Euratom/UKAEA Fusion Association San Diego.

Ledoux, Y., Lasseux, D., Favreliere, H., Samper, S., \& Grandjean, J. (2011). On the dependence of static flat seal efficiency to surface defects. Int. J. Pres. Ves. E Piping, 88, 518-529. doi 10.1016/j.ijpvp.2011.06.002 Malek, M. A. (2006). Pressure Relief Devices: ASME and API Code Simplified. New York, USA: McGraw-Hill.

Marie, C., \& Lasseux, D. (2007). Experimental leak-rate measurement through a static metal seal. J. Fluids Eng., 129, 799-805. doi 10.1115/1.2734250

Marie, C., Lasseux, D., Zahouani, H., \& Sainsot, P. (2003). An integrated approach to characterize liquid leakage through metal contact seal. Euro. J. Mech. E Env. Eng., 48, 81-86.

Müller, H. K., \& Nau, B. S. (1998). Fluid Sealing Technology: Principles and Applications. New York, USA: Marcel Dekker, Inc.

Nouailhas, D., Cailletaud, G., Policella, H., Marquis, D., Dufailly, J., Lieurade, H. P., Ribes, A., \& Bollinger, E. (1985). On the description of cyclic hardening and initial cold working. Engineering Fracture Mechanics, 21, 887-895. doi 10.1016/0013-7944(85)90095-5 three parameters. Technical Note no. 902 National Advisory Committee For Aeronautics NASA, Washington DC, USA.

Singh, A., \& Bernstein, M. D. (Eds.) (1983). Testing and Analysis of Safety / Relief Valve Performance. United Engineering Center New York, USA: ASME. Proc. of ASME conferences.

Song, X.-G., Jung, J.-H., Lee, H.-S., Kim, D.-K., \& Park, Y.-C. (2010). 2-D dynamic analysis of a pressure relief valve by CFD. In S. Chen, \& H. Wu (Eds.), Proc. 9th WSEAS Int. Conf. on Applied Computer and Applied Computational Science (ACACOS'10) (pp. 136-140). Hangzhou (April 11-13), China: WSEAS Press.

Song, X.-G., Park, Y.-C., \& Park, J.-H. (2013). Blowdown prediction of a conventional pressure relief valve with a simplified dynamic model. Math. $\mathcal{E}$ Comp. Modelling, 57, 279-288. doi 10.1016/j .mcm.2011.06.054

Thompson, M. K. (2007). A multi-scale iterative approach for finite element modeling of thermal contact resistance. PhD thesis, Dept. of Mechanical Engineering, Massachusetts Institute of Technology, Cambridge, USA.

Thompson, M. K. (2011). A comparison of methods to evaluate the behavior of finite element models with rough surfaces. Scanning, 33, 353-369. doi $10.1002 /$ sca. 20252

Thompson, M. K., \& Thompson, J. M. (2010a). Considerations for the incorporation of measured surfaces in finite element models. Scanning, 32, 183-198. doi $10.1002 /$ sca. 20180

Thompson, M. K., \& Thompson, J. M. (2010b). Methods for generating probabilistic rough surfaces in ANSYS. In Proc. 20th Korea ANSYS User's Conf.. Gyeongju (Sep. 9-10), South Korea: ANSYS Inc.

Vallet, C., Lasseux, D., Sainsot, P., \& Zahouani, H. (2008). Numerical determination of sealing performance of a rough contact: Real versus synthetic fractal surfaces. In Proc. ASME Pressure Vessels $\mathcal{E}$ Piping Conf. (PVP2008) PVP2008-61213. Chicago (July 27-31), USA: ASME. doi 10.1115/PVP2008-61213

Vallet, C., Lasseux, D., Sainsot, P., \& Zahouani, H. (2009). Real versus synthesized fractal surfaces: Contact mechanics and transport properties. Tribology Int., 42, 250-259. doi 10.1016/j.triboint.2008.06.005 


\section{Nomenclature}

Abbreviations

BC Boundary Condition

EPP Elastic-Perfectly-Plastic

FE Finite Element

FEA Finite Element Analysis

860 FPP Fluid Pressure Penetration

MLKH Multilinear Kinematic Hardening

PRV Pressure Relief Valve

SSC Stress-Strain Curve

Variables, Constants

865

$\sigma \quad$ stress

$\Delta \sigma \quad$ stress range

$\varepsilon \quad$ strain

$\Delta \varepsilon \quad$ strain range

$\varepsilon^{\text {tot }} \quad$ total strain

${ }_{870} \varepsilon^{\mathrm{p}} \quad$ plastic strain

E Young's (elasticity) modulus

$\mu \quad$ Poisson's ratio

$E^{\mathrm{p}} \quad$ tangent (plasticity) modulus

$\sigma_{\mathrm{y}}, \bar{\sigma}_{\mathrm{y}} \quad$ nominal and average yield stress

$875 B, \beta$

$\mathrm{R}-\mathrm{O}$ model constants

$P_{\text {set }}, P_{\text {op }} \quad$ set and operational pressure

$L_{\text {seat }} \quad$ length of valve seat

$R_{\mathrm{or}} \quad$ radius of orifice

$\Delta_{\text {sp }} \quad$ spring displacement

$880 n$

fluid type power-law exponent

$r_{\text {in }}, r_{\text {out }} \quad$ inner and outer radii of the valve seat

$r_{\mathrm{fpp}}, D_{\mathrm{fpp}}, N_{\mathrm{fpp}} \quad$ radius, depth and number of FEs of the macroscopic FPP correspondingly

$F_{\mathrm{or}}, F_{\mathrm{ma}}, F_{\mathrm{mi}} \quad$ orifice, macro-fluid and micro-fluid components

885 of the spring force correspondingly

$F_{\text {seat }}, F_{\text {tot }} \quad$ additional "seat" component of spring force and total spring force correspondingly

\section{Subscripts, Superscripts}

el elastic

890 pl plastic

vM von Mises

eq equivalent

tot total 